\section{Wonders of the Great Barrier Reef}

By T. C. Roughley. Pp. xiii $+282+51$ plates. (Sydney and London: Angus and Robertson, Ltd., 1936.) $15 s$.

7 HIS is a popular book on living animals by a writer who is interested in them as such. It undoubtedly achieves its object, which is stated in the introduction, namely, the encouragement of interest in the Great Barrier Reef and the explanation of its magnificent fauna and its flora in such a way that the lay visitor can understand what he is looking at.

Mr. Roughley's style is of a pleasing simplicity touched here and there with a subtle humour. His calm narration of startling events, such as that of the diver who had his head in a shark's mouth and escaped (p. 226), might well serve as a reproach to the impassioned journalism found in some accounts of 'foreign parts' and their animals. Chapter xvii, "Wealth from the Reef", contains a useful summary of the fisheries and the value of their products, which range from vitamins to shirt buttons. One may be allowed a little doubt as to the incessant activities of killer whales mentioned on pp. 137 and 265 .

Special mention must be made of the thirty-six coloured plates. Although unfortunately one or two are out of register, the remainder are examples of photographic reproduction of a very high order. The resemblance to life achieved by some is quite startling.

Mr. Roughley must be complimented on the production of a pleasing, interesting and informative book.

\section{Food Values :}

What they Are and How to Calculate Them. By the late Margaret McKillop. Revised and brought up to date by Elsie C. Mottram. Pp. xi+155. (London : George Routledge and Sons, Ltd., 1936.) 3s. 6d. net.

$\mathrm{O}^{\mathrm{N}}$ the death of Margaret McKillop in 1936, the publishers of this book entrusted its revision to Mrs. E. C. Mottram. Considerable alteration in format, as well as the addition of new tabular matter and the modernization of the text that one of the most rapidly moving of applied sciences demands, have resulted in as useful and handy a volume as could well be required by housewife or student of social science.

The reviser has, for the most part, eschewed controversial matter, confining herself to the statement of universally accepted dietetic principles and the publication of well-established figures for the com. position and analysis of food. She has, however, drawn one false conclusion from the complementary investigations of the Mellanbys and of Bruce and Callow : it is certain that bone-meal, for example, or any other food source of assimilable phosphorus would be as effective as cod-liver oil, or other form of vitamin $\mathrm{D}$, in combating any rachitogenic effect of brown bread. The remarks of the author on this matter savour a little of the 'faddism' that she so rightly condemns and otherwise rigorously eschews.
Projective Geometry

By Prof. Boyd Crumrine Patterson. Pp. xiii +276. (New York : John Wiley and Sons, Inc.; London : Chapman and Hall, Ltd., 1937.) 17s. 6d. net.

DROF. CRUMRINE PATTERSON declares that his motive in writing this text-book of projective geometry was "the feeling that a more complete discussion than is usual in elementary textbooks is desirable". He thinks that in this way the supplementing of the text does not occur so often and the instructor has more time to devote to discussion, analysis and solution of problems.

The method adopted is that of synthetic geometry, and the development of this method is intuitional and based on the student's earlier knowledge of the elementary geometry of the schools. As distinguished from the usual elementary treatment, there is a careful distinction made between projective and nonprojective ideas, while the principle of duality is developed in some detail. Further, the proofs of some of the earlier theorems are separated into steps and that of the fundamental theorem is built up on the concept of a net of rationality as a line. The theory of the imaginary elements is also introduced in some detail and is applied to various construction problems. Finally, there is a short discussion on the general projective group transformations on a plane and some of its sub-groups, of which the most notable is, of course, the metric group. In this way, the geometry of Euclid is shown to be a special case of projective geometry. There is material enough in the book for a full year's course.

Reactions of Hydrogen with Organic Compounds over Copper-Chromium Oxide and Nickel Catalysts By Prof. Homer Adkins. Pp. ix +178 . (Madison, Wis. : University of Wisconsin Press, 1937.) 3 dollars.

7 HE present volume deals with the development of high-pressure hydrogenation as a tool for use in synthetic organic chemistry and more particularly with the use of black copper-chromium oxide catalyst. Prof. Homer Adkins, his staff, and research students, have made this catalyst peculiarly their own : it is particularly suitable for the hydrogenation of aldehydes and ketones to alcohols, of esters to alcohols, of amides to amines, but is notably inactive for the hydrogenation of the benzenoid nucleus, so that it may be used to hydrogenate aryl compounds without saturating the ring. The procedure for the preparation of this catalyst is given in detail, as also the details of the pressure apparatus and the method of operation.

The bulk of the book is given over to the description of the various types of reaction studied, and the conclusions reached. It is essentially a practical treatise, and therefore all the more valuable; actual figures of temperature, time, quantities taken, yields, are all given.

The reviewer's treatment of it has been to write his name in it and put it on the shelf reserved for books frequently consulted; there will be many others who will do the same.

E. F. A. 